\title{
CORRIGENDUM
}

\section{A meta-analysis of cardiovascular events in intermittent androgen-deprivation therapy versus continuous androgen-deprivation therapy for prostate cancer patients}

C Jin, Y Fan, Y Meng, C Shen, Y Wang, S Hu, C Cui, T Xu, W Yu and J Jin

Prostate Cancer and Prostatic Diseases (2016) 19, 429; doi:10.1038/pcan.2016.48; published online 27 September 2016

Correction to: Prostate Cancer and Prostatic Diseases; advance online publication 6 September 2016; doi:10.1038/pcan.2016.35
Following publication, the authors noticed that the second author's contribution was not properly addressed. Y Fan should be listed as co-first author. 